This is an Open Access article, distributed under the terms of the Creative Commons

Attribution licence (http://creativecommons.org/licenses/by/4.o/), which permits unrestricted re-use, distribution, and reproduction in any medium, provided the original work is properly cited.

doi:10.101 7/So1 44686X160oo362

\title{
Imagined bodies: architects and their constructions of later life
}

\author{
CHRISTINA BUSE*, SARAH NETTLETON*, DARYL MARTIN* \\ and JULIA TWIGG ${ }^{\dagger}$
}

\begin{abstract}
This article comprises a sociological analysis of how architects imagine the ageing body when designing residential care homes for later life and the extent to which they engage empathetically with users. Drawing on interviews with architectural professionals based in the United Kingdom, we offer insight into the ways in which architects envisage the bodies of those who they anticipate will populate their buildings. Deploying the notions of 'body work' and 'the body multiple', our analysis reveals how architects imagined a variety of bodies in nuanced ways. These imagined bodies emerge as they talked through the practicalities of the design process. Moreover, their conceptions of bodies were also permeated by prevailing ideologies of caring: although we found that they sought to resist dominant discourses of ageing, they nevertheless reproduced these discourses. Architects' constructions of bodies are complicated by the collaborative nature of the design process, where we find an incessant juggling between the competing demands of multiple stakeholders, each of whom anticipate other imagined bodies and seek to shape the design of buildings to meet their requirements. Our findings extend a nascent sociological literature on architecture and social care by revealing how architects participate in the shaping of care for later life as 'body workers', but also how their empathic aspirations can be muted by other imperatives driving the marketisation of care.
\end{abstract}

KEY WORDS - architects, body work, later life, imagined bodies, residential care home design.

\section{Introduction}

This article rests on the premise that architects play a significant role in the design of care for later life, not only in a literal sense of crafting physical

* Department of Sociology, University of York, UK.

$\dagger$ Department of Sociology, University of Kent, Canterbury, UK. 


\section{Christina Buse et al.}

spaces and places, but also by their participation in the production and reproduction of caring practices, through their anticipation of how users may inhabit the eventual buildings they design. Drawing on qualitative data generated by interviews with architectural professionals, our findings complement previous sociological research into architects' accounts of their work, which found that they 'rarely think about the human body' (Imrie 2003: 52). A set of related concepts - 'body work' (Twigg et al. 2011), 'imagined bodies' (Kerr 2013) and 'the body multiple' (Mol 2002) - guide our analysis, where we find that when designing for care, especially in later life, architects envisage a variety of bodies in quite nuanced ways. Their empathetic engagement with users places them as key professionals allied to those - such as clinical practitioners - who are more usually associated with care. Architects, we suggest, are cognisant of lived bodies as well as buildings. However, their conceptions of bodies, and ageing bodies in particular, in the context of care harbour tensions that surface as they navigate the competing ideological and pragmatic demands that impinge on their day-to-day architectural practices. They work critically with competing conceptualisations of ageing bodies although, as we shall see, efforts to resist dominant discourses of ageing can often result in their reproduction of these narratives. We therefore frame our analysis with a brief overview of the literature on the interconnectedness of architectural design and ideologies of caring. We then introduce our conceptual tools and study methods before discussing our empirical material that casts light on architects' imagined bodies in the context of residential care in later life.

\section{Architecture and ideologies of care}

Health and social care settings are material expressions of welfare ideologies (Sloane and Sloane 2003). Architectural practice reproduces prevailing ideals and, through the design of buildings, contributes to the fabrication of those who populate them, such as 'the patient', 'the child', 'the nurse' and 'the user' (Prior 1988). Allen (2006) suggests that architecture holds an 'ambient power', with buildings exerting a degree of agency in orchestrating the movements and affective responses of those inhabiting them ( see also Rose, Degen and Basdas 2010). More than simply acting as repositories of symbolic power or ideological meaning (Jones 2011), buildings help to enact ideologies - of care, health and wellbeing-through the social practices they enable and encourage.

When designing residential care homes, architects can be said to give shape to the settings where care will take place, and thereby have the potential to reformulate philosophies of care. Andersson (2015) explored how socio-political visions of care for later life were articulated in design 
competitions throughout the 2oth century in Sweden, where architectural plans became influential within evolving welfare regimes. He identified an aspiration to develop humane and personalised care, and this forms a key trope throughout the 2oth century, even if eventual buildings reveal national variations. Bromley's (2012) exploration of architects' operationalisation of person centredness in contemporary hospital design, for instance, reveals how architects imported hospitality-sector designs which sought to disguise the hospital as a site of clinical care. This chimes with Heathcote's observation that health-care settings must 'attract patients', with 'the hybrid of hotel and mall ... emerging as one of the key contemporary models from the USA to Japan' (2010: 89). These design models seek to adjust the feeling of the hospital to counter the logic of biomedicine and scientific rationality and are part of a more profound shift towards a neo-liberal subjectivity, in which the patient is reconstituted as a consumer and where the practices of health care are played out in hybridised sites of consumption (Martin et al. 2015). It seems likely, therefore, that architects may similarly configure residential homes as hybrid sites through competing narratives and contested meanings.

Gubrium and Holstein's (1999) ethnomethodological exploration of 'the nursing home' finds that the term itself is generative of meanings. As a 'membership categorisation device', it 'guides and ramifies body talk relevant to disease, care giving and dying' (1999: 519). They argue that the 'nursing home':

...frames the body in a way that other sites, such as the hospital, do not. While the hospital as a discursive anchor might accord the body similar status in the short term, its 'gaze' does not have as culturally focused a relevance to old age, nor is it as sustained an anchor for bodily description. The hospital, more than the nursing home, discursively anchors recovery as much as decline and, in that sense, constructs a more positive surface of bodily signs for people of all ages. (1999: 520)

More widely, in media images the care home remains imbued with negative representations of 'feared old age' (Gilleard and Higgs 2011), continuing to anchor the ageing body in discourses of decline. Nonetheless, representations of spaces for old age are changing, reflecting wider shifts in relation to the representation of ageing (Laws 1997). Discursive constructions like the 'third age' and the 'baby boomers' have become widely familiar (Gilleard and Higgs 2010; Twigg and Majima 2014; Ylänne 2012), with older people presented as active and independent consumers of care. These multiple discourses, as we shall see, impact on the ways architects imagine older people. Although as Gubrium and Holstein argued, the 'residential care home' discursively anchors the body, it now does so in more varied and flexible ways. 


\section{Christina Buse et al.}

\section{Imagined bodies and body workers in health and social care}

Ideologies of care intertwine with competing ontologies of bodies. Modern 'Western' medicine, long dominated by a 'mechanical', 'functional' body and an objectified view of the patient (Leder 1992), now engages with the 'lived body' (Prentice 2013), and is located within philosophies that privilege 'person-centred' and 'relationship-centred' approaches (Shapiro 2008). It has, however, long contained orientations that emphasise objectifying practices of medicine - 'slicing', 'probing', 'talking about', 'measuring' and 'counting' bodies (Mol 2002: vii). As a result, practitioners routinely move between different conceptions of the body, such as the 'lived' body talked about by patients and the 'mechanical' body or 'measured body' of diagnostic practices (Prentice 2013).

Previous literature has tended to focus on how notions of the body emerge from 'hands on' work on bodies, and those professionals who carry out such 'body work' (Twigg et al. 2011 ). More recently, a growing exploration of 'imagined bodies' has led to a call for an extension to the concept of 'body work' to include 'multiple bodies in care work, including virtual bodies rendered visible by technical devices' (Kerr 2013: 467; Lupton 2014), as well as the examination of a wider range of professional roles. For example, Kerr's (2013) analysis of practitioners' accounts of their decisions, in the context of the provision of assisted conception, finds that those involved in the allocation and delivery of the service are touched by the emotional consequences of their decisions, even where they do not meet the service users in person. They are, she argues, sensitive to the 'imagined bodies' in receipt (or not) of services and showed 'displays of empathy and shared frustrations' (Kerr 2013: 476) associated with their decisions. In the context of pharmacy practice, Jamie (2014) similarly explores how pharmacists work with 'symbolic' as well as physical bodies, and with the multiplicity of bodies they encounter in their roles as retailers, dispensers and public health practitioners.

Moving to architects as designers of care, 'body work' can give analytic purchase to explore how they imagine the bodies of those who they anticipate will populate their buildings. Research to date suggests that attention to bodies in architecture, and the range of bodies attended to, is limited. Imrie, for example, set out to explore the 'bodies in mind' as 'conveyed by architects' self-testimonies' (2003: $5^{2}$ ) and found these to be relatively 'partial and reductive conceptions of the human body' (2003: 63). The feminist philosopher Elizabeth Grosz (2001) has written extensively on the need for architectural practice to engage with the mess of corporeality and difference, and most particularly the need for architecture to be explicit about embodiment and the relations between sexualised and racialised bodies. 
She argues for a continuing political engagement, whereby architects relentlessly question their ideas as to how best to configure spaces, bodies and their interconnections. She writes:

The relation between bodies, social structures and built living and work environments and their ideal interactions is not a question that can be settled: the very acknowledgement of the multiplicity of bodies and their varying political interests and ideals implies that there are a multiplicity of idealized solutions to living arrangements, arrangements about collective coexistence, but it is no longer clear that a single set of relations, a single goal or ideal will ever adequately service as the neutral ground for any consensual utopic form. (Grosz 2001: 150)

For Grosz, architecture, like any discipline, must engage with a somatic politics.

Imrie's study of architects working in the United Kingdom comes to a similar conclusion. He found that in architectural practice and training the body, in all its diversity, was largely absent; and 'if the body did figure at all', it was a Cartesian, geometric and essentialised body, 'little more than an object with fixed measurable parts' which was 'neutered and neutral, that is without sex, gender, race or physical difference' (Imrie 2003: 47). On those occasions where architects anticipated the use of buildings, they did so by drawing on their own personal experiences with 'their own bodies as the dominant point of reference' (2003: 57), a finding replicated in our data as we discuss below. Imrie also found that the body was 'rarely conceived as an organic fleshy, entity', and 'more often than not, the human body is defined as "people" who populate designs, or as collective categories of users predetermined by the function of the building being designed' (2003: 57). Imrie argues for a more reflexive form of architectural design that 'recognises, and responds to, the diversity of bodily needs in the built environment' and, like Grosz, an architecture which is 'open minded' and 'sensitised to the corporealities of the body' (Imrie 2003: 64).

Our discussions with architects undertaken over a decade after Imrie's study indicate that they do appear, at least, to appreciate a diversity of bodily needs in ways that Imrie's study participants did not. This could well be because our work addressed design projects for the care for men and women in later life, with the spatial form of the residential care home anchoring a culturally problematic body (Gubrium and Holstein 1999) rather than a generic body - indeed, in recent guidance to architectural professionals, the residential setting is identified as a potential barrier to thinking about designing in age-friendly ways (Handler 2014: 17). It may also reflect ideological shifts towards personcentred and non-institutional forms of care outlined above, in concert with a politicisation of bodies in all their diversity. Moreover, in building design since the end of the 2oth century, embodied issues have been foregrounded in legislation relating to, for instance, issues of access and inclusive design 
(Imrie and Luck 2014; Soldatic, Morgan and Roulstone 2014). Nevertheless, the prominence of the architects' rehearsal of multiple imagined bodies throughout the interviews was striking, as we explore in the following sections.

\section{Study and methods}

To begin to unravel architects' work in the care home sector we undertook 20 semi-structured interviews with 26 architectural professionals in 2014-15, with some single interviews involving two or three architects. Maximum variation sampling led to the inclusion of architects from large and small firms, and those whose portfolios included a variety of projects in different sectors of care, ranging from firms working for large privatesector care providers to those working with local authorities, and firms working with smaller charitable organisations. All participants worked on projects in other areas, but all had a portfolio of care projects they could discuss. Of the 26 architects and designers interviewed, seven were female, as might be expected in a profession still dominated by traditional gender norms (Sang, Dainty and Ison 2014). Participants were asked to talk us through the various processes of the planning, construction and completion of buildings. Questions included: How are the architectural briefs for care homes negotiated? What issues arise in site-specific contexts? How do they as architects communicate with clients, builders, planners and other stakeholders? What types of knowledge about the care needs of eventual users are sourced and how are these translated into design?

As we familiarised ourselves with the data, we were struck by the amount of body-related talk. Following initial coding, we revisited the data using 'body work', 'imagined bodies' and the 'body multiple' as sensitising concepts. It became apparent that architects were anticipating bodies within care settings, especially as they spoke about strategies by which they might attend to the needs of users. We identify several such strategies described as they reflected on designing for later life. Our analysis also reveals how they work with particular constructions of 'ageing bodies' and how they reproduce and yet also try to challenge discourses of ageing. The architects' strategies for imaging bodies and their constructions of ageing also rub up against, or at least have to engage with, the imagined bodies conceived by other stakeholders involved during the design process, as we explore in more detail below.

\section{Strategies for imagining bodies}

Strategies for imagining bodies took various forms of empathetic engagement with users including: envisaging oneself as a potential user, 
referencing one's own experience of physical environments, drawing on the presumed needs and experiences of older relatives, role play within projected design settings, and consulting with users. Through these processes various bodies were conceived of in the reflections of our participants, and through this the architects engaged in forms of body work, understood as the rendering of bodies as visible within particular material contexts.

Interviews opened with questions on approaches to designing residential homes and it was striking how some participants foregrounded a living body. One female architect immediately focused on the body at the start of the interview when asked how she would approach designing a care home.

I think you start with the body, in a way. Like how you come into a space, how you see it, whether you see it or not, so you're thinking about how someone sees, how someone feels, acoustics. Is it going to be too noisy? Especially with dementia, noise and lighting are key. (Interview 11 )

She goes on to explain how anticipating the bodily experience of service users, and most especially those with dementia, is a 'challenge' requiring the architect to 'step into the shoes' of someone who is differentially embodied. As another architect said, 'I think the most important part is the empathic process', before posing the question of 'how do we create that empathic process?' (Interview 7). This apparent sensitivity to the lived bodily experience of older people with dementia was seen as necessary for meeting acceptable standards of design in this field, with this particular architect even describing it as an 'obligation'. We can situate these reflections within a growing demand for empathic and emotion work in medical (Kelly 2014; Shapiro 2008) and design professions (Suri 2001), and as a form of contemporary affective labour (Pedwell 2014). In this, our data may be tapping into wider ideological changes as compared with the late 2oth century, when Imrie's research was undertaken, as well as increased research within architectural circles on the topic of designing in age-sensitive ways (Handler 2014).

Nevertheless, consistent with Imrie's (2003) research, we found that architects were self-referential, drawing on their own experiences to imagine the lived bodily experiences of later life. In particular, they drew on aspirations for anticipated care needs - for themselves or their relatives: 'You always keep thinking, would I want my mum to do that, or would I want my mum to live there, and I always try and put myself in someone's shoes' (Interview 8). A few employed strategies that were more concrete, using their bodies to experience settings empathetically and pragmatically as they developed:

I've said to my colleagues when this latest scheme is finished, the first thing we're going to do is get in a wheelchair and we're going to wheel ourselves round the building and see how wheelchair-friendly it is. (Interview 3) 


\section{Christina Buse et al.}

This suggests a process of imagining as 'perceiving in the hypothetical mode', as understood by Murphy in his discourse analysis of how architects work in configuring the eventual user experience of their buildings (2004: 277). Other architects created 'mock-ups' of care home spaces, physically putting themselves in the place of the user: 'I'm lying in bed here, can I see the toilet?' (Interview 8). These techniques can create a 'powerful feel for bodies' (Prentice 2013), cultivating strategies of 'empathic design' (Kouprie and Sleeswijk-Visser 2009).

While this body work sought to provide empathetic insight into user perspectives, there is however the potential to reinforce relations of difference between 'the emphasiser' and the 'other' (Pedwell 2014). This 'othering' was evident in the language used by some, such as the ubiquitous use of 'little' as in 'little old ladies', 'designing a little kitchen area' with a 'little table' and also references to 'poor old lady' and descriptions of people with dementia as 'very sick' and 'very frail'. This reflects how care homes continue to anchor particular (gendered) repertories and images of ageing, including infantilising discourses (Hockey and James 1993). However, in other cases self-referential work had the potential to engender 'shared vulnerabilities' (Shildrick 2001), and unlock the emotional challenges associated with negotiating unfamiliar space. As one architect comments:

I mean we all suffer from problems of way-finding. I expect you, like anybody else, have been in a busy airport, late for the gate, not being able to find where you want to go, rushing towards the gate having a panic attack. (Interview 5)

To some extent, this ability to invoke 'shared vulnerabilities' depends on the architects' social location. Interviewee 5 went on to draw on her own experiences of growing older in imagining these embodied challenges: 'when you're young you can't imagine what it's like to be old, and as you get older this awful awareness sinks in!' In contrast, a younger male architect distinguished his own preferences from that of older residents, dichotomising the design needs of young and old (Woodward 1991): 'the ground floor is popular which kind of goes against what we would want as younger people' (Interview 2).

The participants did, however, go beyond personal experience, and a further strategy was the recourse to training resources and written guidance such as those issued by the University of Stirling's Dementia Centre to guide their design and to grasp the visual, cognitive, auditory, sensory needs of people with dementia. The Stirling Standards seek to encourage empathic engagement; 'written in first person to ensure that dementia friendly design is understood from the perspective of the person with dementia' (Dementia Services Development Centre 2012: 1). They highlight the diverse sensory 
aspects of the space: reducing noise, 'plenty of light', the visibility of staff and relatives and 'good colour/tonal contrast' in the toilets. Training workshops encouraged architects to use their bodies to imagine the experiences of people with dementia, such as 'putting on gloves' whilst attempting everyday tasks. This guidance was often felt to provide a 'way in' to the experience of ageing, which would not otherwise be accessible, as one architect said: 'other than having a personal experience with a grandma that was in a care home, we would not be able to perceive that side' (Interview 7).

Nonetheless, some architects found these prescriptions to be normative and restrictive. Self-referentiality at times trumped evidence-based guidance which details the importance of bright and primary colours in care home settings, with some architects eschewing this on the basis that it is not what people would want in their own homes, and thus revealing a propensity for the imposition of the designer's own values and aesthetic. Others argued that 'reliance upon published information' is no substitute for spending 'time actually in a care home with people with dementia' (Interview 1) and appreciating their personalised and individualised needs. One described how 'we don't have much contact with people with dementia or older people in care' and so 'I've tried to make an effort to get to know people with dementia', even joining the board of a local care home (Interview 1 1). Another, who refurbished existing properties, emphasised the importance of regular 'face-to-face' consultation with users throughout the process (Interview 3). In general, however, consultation with users was limited, taking place only 'post-occupancy'. Furthermore, architects varied in the extent to which they felt user engagement should be incorporated into the design process, particularly with frail older people with dementia who were sometimes described as too 'difficult' to consult with, due to their 'confused state'.

Consultation with service users and staff was more common among those working for small charities, local authority or National Health Service facilities, or involved in the refurbishment of existing care homes or sheltered housing. The extent to which such consultation took place depended on who the client was and whether it was written into the brief, reflecting the collaborative and contingent nature of the project work-a point we return to below. Discussions with users often exposed the limits of imaginative perspective taking (Imrie and Luck 2014), as care home residents raised issues 'that probably you and I wouldn't even dream about' but 'were massively important' (Interview 3) to them. Architects spoke about getting 'little gems from service users' regarding how their designs could be improved to accommodate bodily needs and preferences; for instance, altering the width of bathroom doors following feedback from a service user that 'when you go from a corridor area, to a bathroom area, the 


\section{Christina Buse et al.}

hoist can wobble just a little bit and slip', causing him to 'bang his elbow on the doorframe' (Interview 2).

These examples focus on bodily impairment, reflecting how, as Gubrium and Holstein (1999) argue, the care home discursively orientates body talk towards disease, care-giving and dying, rather than other aspects of embodiment. However, consultation with users and personal experiences with relatives could facilitate a more balanced understanding of the lived body. One architect reflected that when he 'entered the field of elderly care design' he had a rather stereotypical, 'idealised view of what older people are like'. However, through spending time in care homes and 'working with people directly' this 'opens you up to that spectrum' in terms of the diversity among older people (Interview 16). Another architect described how consultation with users highlighted various everyday concerns: how important 'having some identifiable personal space outside' is, 'where and whether a settee would fit in' or 'what would the tiles be like in the bathroom?' (Interview 3). His personal account of his parents' physical and emotional challenges associated with their changing needs also illuminates the complex entanglements of bodies, places and things in negotiating meanings of 'home':

My parents live in a little bungalow; my dad's 86 , my mum's 84 . We think mum's got some sort of early onset dementia ... they have carers going four times a day, and that's been a really good example of how they're having to change and how upsetting it is ... there's a lovely little round coffee table in the middle which is mum's pride and joy, and it got in the way of the walking frames ... You'd have thought we'd asked them to walk across the Sahara to give up this coffee table, that's how important it is to people. And no doubt someday, I'll be the same, that I'll be not wanting to lose something out of my house that is necessary to enable me to get about. (Interview 3)

This quotation figures care as an art of dwelling that 'enacts being-at-home by reassembling bodies, emotions, technologies, and places in highly specific, complex ways and often fragile and precarious ways' (Schillmeier and Domènech 2009: 288). We might discern processes of othering (Pedwell 2014) and a characterisation of older people as potentially irrational through the use of absurd humour here, but we also hear the voice of a practitioner who seeks to attend to the detail of care work in practice - as he articulates a sensitivity to the salience of personal effects and material objects.

It was rare for architects to know the personal histories of those who would reside in their buildings. Thus, architects tended to 'flesh out' service user's lives through the use of imaginative strategies whereby they reconstructed idealised 'embodied biographies' (Williams 2000), drawing on familiar generational motifs, as indicated here: 'A lot of their working 
adult life would have been outdoors all year so they'll be used to being outdoors so having what we call "the wind on the face"" (Interview 2). They also constructed 'narrative vignettes' (Blythe and Wright 2006) that ascribed histories, personalities and interests to virtual users, as in the comments about 'an old man who wants to sit and talk about his days in the army for an hour before they talk about whether he would prefer a small garden outside his apartment' (Interview 3). Naming is also a significant part of personification (Prentice 2013), illustrated by the use of names such as 'Mavis' and 'Elsie', as in the comment 'we'll have an oven so that ... Elsie can make cakes when she wants to' (Interview 3), which in the UK context have generational associations. Yet these characters remain 'quasi-subjects' (Prentice 2013), potentially 'unconvincing because they are composites' (Blythe and Wright 2006: 1141). These imaginings therefore reproduce cultural tropes connoting pre-war generations, as well as gendered images of old age and elder care. It is to these wider images and constructions of ageing bodies that we now turn.

\section{Constructions of the ageing body}

While architects made efforts to engage creatively with the fleshy, lived body of residents, their discussions were nonetheless anchored in dominant cultural repertories around ageing, at times reproducing stereotypical depictions of old age. In seeking to reconstruct the daily experience of the service user, architects' narratives could reduce older people to bodily needs and (dys)functions. There was a focus on the 'body zones' of the bedroom and bathroom in their accounts (Imrie 2004: 748). Indeed, when asked about approaches to designing residential homes, a number of the architects emphasised how they 'start with the bedroom' when designing for care and in this space imagine the daily life of the user. Discussion of these 'body zones' summoned images of dependent, leaky bodies:

...if they need help with everyday tasks, that help should be able to be given to them, discreetly and comfortably. So if someone needs help going to the toilet then they've got an en suite there, there's enough room for the staff to help them ... if someone has had an incontinence accident and they need to be washed they should have a shower in their en suite, in that privacy, not having to sort of come out of the bedroom down the corridor for everyone to see them ... Mavis has wet herself again. It's that dignity. (Interview 8)

Such discussions construct the ageing body in terms of disability and dysfunction. Therefore, in contrast to architectural design more generally, where there is a presumption of able bodies (Imrie 2003), the care home 


\section{Christina Buse et al.}

is embedded within images of frailty, decline and dependency (Gullette 1997), dominated by routines of bed and body work (Gubrium 1997). Such images of 'leaky' bodies were also gendered (Lawton 1998), generally focusing on women. These assumptions about decline were embedded in discussions of 'flexible' spaces that are able to adapt to deteriorating mental and physical abilities.

Yet architects' constructions also drew on newer, more positive images of ageing, describing older people as 'embracing life', having 'so much opportunity', 'being part of a vibrant community' and having a 'nice lifestyle' within the care home. These changing concepts of the lifecourse reflect a 'new generation' of spaces for old age (Barnes 2002; Ylänne 2012) that increasingly take their architectural cues from the hotel and leisure sectors. Just as hotels offer grades of accommodation-standard en suite, premium, and so on - so too do some care homes. One architect illustrated how in some care homes he designed 'the bedroom at three different standards, bronze, silver and gold' (Interview 7), and another had designed 'premium' bedrooms for one care home (Interview 20). Others describe their designs as resembling 'luxury' hotel-like spaces, with residents 'receiving a service' and an 'experience':

You are going in to a hotel and we will provide services, we will provide fine silver service dining ... Your morning breakfast and croissants there overlooking that view. They have got very nice fitted out furnishings; you've got wallpaper so it has got that elegancy. It has got nice chandeliers. Surrounded by gardens... (Interview 2)

Cinemas, shops, hair salons, cafes and bars are incorporated into the design of care homes, suggesting places of consumption and active leisure. With their emphasis on 'luxury' and 'elegance', they present a vision of life that is implicitly classed and remote from institutional models associated with welfare and need.

Not all architects were comfortable with the incorporation of 'hotel-like' facilities and services into care settings, preferring what was construed as an alternative 'domestic' model. This too, of course, could draw on normative models of classed lifestyles. Nonetheless, there was consensus in terms of the need to move away from institutional models of care. Reflecting Bromley's (2012) findings, architects sought to disguise the fact that their building was 'an institution' for the delivery of care. One architect spoke of 'trying to remove the medical connotations completely from people's minds when they are living there' (Interview 2). Interviews are replete with references to 'human scale', 'lack of corridors', 'personalised bedrooms' and shared spaces that encourage active rather than passive encounters and social practices.

Such discussions emphasise personalised, person-centred and consumerorientated services rather than medical care, and yet semantic slippage 
reveals tensions between new models of care and the fact that the residential care home is based on the spatial segregation of older people, and predicated on bodily dysfunction. The same architect who described a shift away from 'medical connotations' and hotel-like 'services' then went on to state:

It's a disease so they are either a danger to themselves or others so need to be looked after. So what we do with the dementia areas is try and design it so we reduce stress levels as if people get frustrated and don't understand their stress levels shoot up and the residents becomes disruptive. (Interview 2)

This quotation returns to medical models of ageing, and images of older bodies as diseased, declining and 'vulnerable', contrasting with depictions of positive ageing earlier in the interview.

This duality in architects' narratives of ageing is embedded within broader cultural images, which dichotomise 'third agers' as active and healthy consumers, with the fourth age as time of dependency and decline (Rees Jones and Higgs 2010). Popular tropes such as the 'baby boomers' surfaced in architects' imaginings of older people. For instance, one contrasted the 'generation of 85 who lived through the war, hard times' to the 'baby-boom generation' who have 'got a bit of money ... had a very good quality of life, moments cruising around the world maybe' (Interview 2). Though the rhetoric of the baby boomer has been challenged as representing a sectional, often classed account in which the significance of cohort is exaggerated (Jönson 2012; Twigg and Majima 2014), it is widely pervasive in the popular culture. It has obvious commercial appeal within the design industry, "presenting a vision of later life that is up-beat, optimistic and forward facing' (Twigg 2012: 1049). As one architect comments, this is a vision which actively sells the care home:

The issue for the client is that typically you are selling your care home to the resident's family, and the resident's family see something that looks like a hotel and thinks it's all rather swish, mum will be well looked after here. (Interview 4)

This consumerist model of care is something that the architects felt that 'a lot of care providers want' because it appeals to those purchasing care which was presumed to be the relatives of potential residents rather than older people themselves. Certainly, research suggests that relatives choosing a care home often interpret the physical environment, including 'good decor and comfortable furnishings', as an indicator of care quality, in the absence of any detailed guidance (Davies and Nolan 2003: 441). Thus, the hotel model removes institutional connotations associated with feared old age, reassuring relatives that 'mum will be well looked after here'. These discussions also reflect the commodification of care, and an increased emphasis on 'branding' and selling care within the competitive market of the contemporary care sector (Holden 2002). 


\section{$144^{8}$ Christina Buse et al.}

These discursive divisions between 'consuming and active bodies' and 'diseased and declining bodies' were also enacted spatially, in the spatial ordering of bodies through design. The architects reported that clients preferred people with dementia to be located on the top floor, excluded from downstairs spaces which constitute the 'public front' of the care home (LeeTreweek 1997):

We were told, for example, that there would be groups of people with more severe dementia ... and we argued with the client that they should be located on the ground floor so they'd get better access to the gardens. And the client was like 'oh', because that's generally not the policy. People with worst dementia go on the top floor ... I suspect that's because it's not so easy for visitors to see and from a selling point of view it's not great to walk in, which is really sad. (Interview 11)

Therefore the design of new, 'vibrant' spaces of ageing is dependent on concealing the 'abject bodies' of people with advanced dementia (Gilleard and Higgs 2011 ), as well as concealing design features that might speak to institutional or medicalised settings. Various design guides stress the importance of access and proximity to outdoor spaces for older residents' quality of life (e.g. Delhanty 2013; Dementia Services Development Centre 201 2; Homes and Communities Agency 2009), and it has been argued that locating residents with dementia on upper floors can act as a barrier to access (Chalfont 2008; Chalfont and Rodiek 2005; Torrington 2006). While balconies may overcome access issues on upper floors (Delhanty 2013), these were often opposed by clients due to concerns with risk. Therefore possibilities for new images and spaces of ageing are constrained by competing notions of 'risky' and 'calculated' bodies, to which we now turn.

\section{Juggling multiple bodies}

Attempts to imagine bodies of users were invariably tempered by the bodies 'imagined' by other participants and stakeholders in the design process. Consequently, we find that architects are engaged in a process of 'juggling' differing ontologies of bodies. These variably enacted bodies may collide; contradicting and constraining each other and yet still 'hang together' (Mol 2002) as the end users who are anticipated as living in the finished building. Architects' design work takes place in the busy series of negotiated compromises, within the clamour of local politics and material constraints (Gutman 2010). Latour and Yaneva (2008) liken the architect to a 'juggler', relentlessly having to respond to a multiplicity of material and political demands. The evolution of design is a fluid process wherein the architect must 'absorb a new difficulty and add it to the accumulation of elements necessary to entertain the possibility of building anything' (Latour and 
Yaneva 2008: 84). Such juggling implies a form of complex affective and empathetic labour, where craft and co-operative practice are combined (Sennett 2009, 2012). What is evident from our analysis is the extent to which designing for care involves collaborating with other body workers such as occupational therapists, physiotherapists and care workers. The following account of a project meeting captures how stakeholders' different conceptions of the body come into conflict in the design process: 'calculated bodies' driven by budget interests; 'declining bodies' as the object of care; and material bodies that need to be mobilised.

...suddenly you've got eight other people, all with different agendas ... who could not agree amongst themselves whether we should have facilities for hoists above the bed ... or whether we should have movable hoists ... And there were so many stakeholders there ... a physiotherapist, another lady was occupational therapist, another lady was going to be paying for staff to come out and hoist people out of bed, so she wanted hoists because it was quicker than having a mobile hoist, so she was driven by a budget, and the cost of moving people around within the apartments once people had occupied them. (Interview 3)

Thus, the body work of architects involves negotiation and struggle over the prioritisation of the differentially imaged bodies of the other body workers involved in the delivery of health and social care. Stakeholders bring with them differing conceptions of the body to their discussions with architects. Discussions with planners were reported as frustrating when people with dementia were purely and merely seen as 'risky' bodies (Phillipson and Powell 2004). An example of this was when one architect's plans to introduce a 'pedestrian bridge' to 'help the local community come into the building' were overruled by the planner as they were perceived to be too risky: 'the planner is like: "Oh bridges? People with dementia? Oh no, you can't have that" (Interview 1 1).

Despite an aspirational focus on the lived body in discussions of architectural design for care, the abstraction of bodies into measurable and quantifiable units (Imrie 2003) dominated interactions with clients and architectural briefs. Initial consultations with clients start with the number of bedrooms, and the amount of space needed per resident in order make the home profitable:

We've got this floor area per resident, that's what the client has worked out gives them best pay back. If they can get 60 residents with 50 square metres maximum per resident then they'll have a cost-effective building. (Interview 4)

These discussions again reflect the commercialisation of care, alongside increased government regulation and standardisation of the spatial allowance per resident, which mean that care homes must be large enough to achieve 'economies of scale' (Holden 2002: 80). 
Architects' experiences of negotiating client briefs varied, however, according to a range of factors including: the procurement process, the type of client, size of the organisation, their relationship to the architect, the type of development (e.g. care home or sheltered housing) and their care philosophy. These factors intersected in complex ways, although initial interviews with architects suggest that larger, for-profit organisations have a stronger focus on commercial issues, as one architect said:

Some organisations have very very very fixed criteria, so they actually call it a product, and that product has an outcome already, and our job then is basically to try and work their product into the site ... they will have standard unit types, standard floor layouts ... they're quite commercial, so they know what their products are ... they know what sells, and they want to make sure that they have unified product throughout all of their schemes, so there's a lot less flexibility. (Interview 18)

In contrast, some architects described small charitable organisations and in some cases local authorities as more user-focused, with housing associations in particular often having a 'flexible' brief which is developed in consultation with the client and service users. However, several architects suggested that in the context of funding cuts, these organisations are growing 'more financially conscious', and increasingly 'have to be self-supporting, and this becomes the sort of driver' (Interview 17). This reflects wider arguments that the marketisation of care can undermine the interests of service users, contrary to the rhetoric of consumer choice and empowerment (Brennan et al. 201 2; Oldman and Quilgars 1999).

Cost efficiency is in tension with the wish to reform care regimes according to standards for dementia-friendly design, with the result that architects become embroiled in juggling competing logics of care (Mol 2008). Some of these logics take on social, aetheticised and normative qualities.

...the care home providers want to have a hotel-like aesthetic, and for me I find that very difficult, because it's not necessarily going to be dementia-friendly. To have somewhere that looks like a hotel is to me indicating to the resident that it's not actually home, it's a hotel and you're going to go home in a few days. (Interview 11 )

Resonating with long-standing debates about the nature of residential care, this comment captures particular tensions around the nature of the space, and whether it is public or private, communal or domestic. Bland's (1999: $55^{8)}$ detailed study of the residential care sector, for example, found amongst care providers 'uncertainty as to whether residential care homes are supposed to be run like hospitals, hotels or domestic residences'. Our interviews show how these tensions can also be found upstream, in the conflicting imperatives and perspectives that architects articulate and negotiate in their designs and routine professional practice. 


\section{Conclusion}

Throughout this paper we have argued that the design process, in the context of residential care, involves a form of 'body work', as architects anticipate and 'imagine' bodies that will populate their buildings. Architectural practice is inherently collaborative and therefore constructions of these 'imagined bodies' are modified by other participants involved in building projects as well as being shaped by competing ideologies of care. Our analysis of architects' accounts, informed by the concepts of 'body work' (Kerr 2013; Twigg et al. 2011) and 'the body multiple' (Mol 2002), reveals how prevailing ideologies of care intertwine with competing ontologies of bodies and logics of care ( $\mathrm{Mol} 2008)$ that are imaginatively constructed through architectural design practices. Academic conceptualisations of the built environment prompt architects to be alert to the embodied, multi-sensual and affective understanding of buildings as experienced by its users (Jacobs and Merriman 2011; Lees 2001; Rose, Degen and Basdas 2010). Our findings are therefore significant because they complement existing research that has suggested that architects work with a generic, Cartesian body, if they think about the body at all (Grosz 1995; Imrie 2003). Indeed, our study reveals that, at least in the area of residential care design, architects work in a way that foregrounds the body and its emotionally charged experience of place.

It may well be that contemporary emphasis on bodies reflects emergent debates around user-centred and 'empathic design' (Kouprie and Sleeswijk-Visser 2009) that are currently being extended to architecture (Imrie and Luck 2014), paralleling a broader emphasis on personcentred and consumer models of health care. Architects appear to engage in the process of what Twigg (2012), in her study of designers of clothing for older customers, refers to as 'apostrophising' the customer, in which presumed characters, preferences and bodily qualities are actively evoked as a means to aid design. That is, our participants imagined their users and enveloped them within detailed narratives of potential spatial practices, affective biographies and moral values, in order to inform the residential plan better, hinting at a reflexive architecture. However, reflexivity on the part of architects is invariably constrained by the compromises that day-to-day professional practice entails. This paper further illustrates that like other care professionals, architects enact the body multiple (Mol 2002), as they 'juggle' with competing stakeholder conceptions of bodies to reach a compromise on the user's body.

This indicates the need for further exploration of the tensions which cut through architects' work, and the intervening factors which may shape, 


\section{$145^{2}$ Christina Buse et al.}

constrain and compromise architectural design for later life. As raised in the HAPPI report (Homes and Communities Agency 2009), a range of factors including commercial constraints, planning and regulation may undermine principles for best practice design. Further dialogue incorporating the perspectives of a range of actors, including care providers, planners, regulators and architects, may be beneficial, and is beginning to be addressed through emerging research such as the DWELL project (http://dwell.group.shef.ac. $\mathrm{uk} /$ ). These issues also need to be situated within the wider policy context of the marketisation of social care and retreat of state funding, in the United Kingdom and elsewhere (Aronson and Neysmith 1997; Brennan et al. 201 2; Fotaki and Boyd 2005), leading to an emphasis on cost efficiency and economies of scale which may compromise user-centred design. Variation in the constraints and contextual factors which shape design for later life could be further explored at a local and international level.

While other body workers, such as clinicians, have been taken to task for focusing on the individualised body of the patient to the neglect of context (Leder 1992), architecture's cosmology is more context-orientated. We might speculate that one reason that architects to date have tended to think less about the individual body is their propensity to think in collective ways, as they orientate towards interactions and flows of people as they inhabit spaces. This issue warrants further research, as does the variety of ways in which architects anticipate the lived experience of users of the buildings. Whilst we are not advancing a determinist account of the capacity of spatial design to effect different practices of care in and of themselves, we do consider architecture to play a significant part in establishing wider understandings of the ageing body and reproducing certain narratives of care. Architects' discourses are interesting not merely because they reflect back wider cultural tensions in how we apprehend ageing bodies, toggling back and forth between narratives of natural decline and normative ideals of successful ageing, but also because architects as a profession are contributing to the atmospherics of care. Their buildings facilitate the feel of ageing in contemporary social worlds and, because of this, we need to know more about where they derive their knowledge of wellbeing and care, and how they enact it through their professional practice.

Whilst our study has been of the architectural profession, these findings suggest the importance of turning the lens to the practices of designers more generally, as part of understanding how later life is 'imagined, performed and experienced in contemporary culture' (Twigg 2012: 1049). Previous studies in the fields of clothing design (Twigg 2012), assistive technology (Fisk 2003; Mort, Roberts and Callen 2013), and information and communication technologies (ICTs) (Östlund 2002, 2005), suggest that their design and marketing similarly draw on - and may inform - particular 
representations of later life and ageing bodies. However, research exploring the practices of such design professionals and their imaginings of ageing and ageing bodies is limited. In the fields of assistive living technologies and ICT design, it has been argued that that there is often a 'lack of fit' between these technologies and the everyday lives of the end user (Milligan, Roberts and Mort 2011 ; Selwyn 2004). Further research examining the practices of designers across different fields - architects included may be helpful in illuminating these issues, exploring the extent and ways in which different types of designers imaginatively engage with experiences of ageing, but also the complexities and competing demands which may constrain practices of design.

\section{Acknowledgements}

This paper reports on research which was supported through funding from the Foundation for the Sociology of Health and Illness for its initial stages and then subsequently by the Economic and Social Research Council, as part of the 'Buildings in the Making: A Sociological Exploration of Architecture in the Context of Health and Social Care' project (reference ES/Moo8398/1). The authors would like to thank Ellen Annandale, Siân Beynon-Jones and Lindsay Prior for their helpful discussions with us throughout the development of this article. Earlier drafts of the paper have been presented at the 2015 British Sociological Association Med-Soc Conference (York, UK) and the 2015 Materialities of Care Conference (York, UK), and the paper has benefited from comments and questions at both events. This research has been reviewed and approved by the Economics, Law, Management, Politics and Sociology Research Ethics Committee at the University of York.

\section{References}

Allen, J. 2006. Ambient power: Berlin's Potsdamer Platz and the seductive logic of public spaces. Urban Studies, 43, 2, 441-55.

Andersson, J. E. 2015. Architecture and the Swedish welfare state: three architectural competitions that innovated space for dependent and frail older people. Ageing Eo Society, 35, 4, 837-64.

Aronson, J. and Neysmith, S. M. 1997. The retreat of the state and long-term care provision: implications for frail elderly people, unpaid family carers and paid home care workers. Studies in Political Economy, 53, 37-66.

Barnes, S. 2002. The design of caring environments and the quality of life of older people. Ageing E Society, 22, 6, $775^{-89}$.

Bland, R. 1999. Independence, privacy and risk: two contrasting approaches to residential care for older people. Ageing $\mathcal{E}$ Society, 19, 5, 539-6o.

Blythe, M. A. and Wright, P. C. 2006. Pastiche scenarios: fiction as a resource for user centred design. Interacting with Computers, 18, 5, $1139-64$. 


\section{Christina Buse et al.}

Brennan, D., Cass, B., Himmelweit, S. and Szebehely, M. 201 2. The marketisation of care: rationales and consequences in Nordic and liberal care regimes. Journal of European Social Policy, 22, 4, 377-91.

Bromley, E. 2012 . Building patient-centeredness: hospital design as an interpretive act. Social Science Ẽ Medicine, 75, 6, 1057-66.

Chalfont, G. E. 2008. The living edge: connection to nature for people with dementia in residential care. In Froggatt, K. A., Davies, S. and Meyer, J. (eds), Understanding Care Homes: A Research and Development Perspective. Jessica Kingsley Publishers, London, $113-35$.

Chalfont, G. E. and Rodiek, S. 2005. Building edge: an ecological approach to research and design of environments for people with dementia. Alzheimer's Care Quarterly, 6, 4, 341-8.

Davies, S. and Nolan, M. 2003. 'Making the best of things': relatives' experiences of decisions about care-home entry. Ageing $\mathcal{E}^{2}$ Society, 23, 4, 429-50.

Delhanty, T. 2013. Housing LIN Factsheet 35: Landscape Design for Dementia Care. Housing Learning \& Improvement Network, London. Available online at http://www.housinglin.org.uk/_library/Resources/Housing/Support_materials/ Factsheets/HLIN_Factsheet35_Landscape.pdf [Accessed January 2016].

Dementia Services Development Centre 201 2. The Stirling StandardsforDementia-friendly Design. Available online at http://www.dementiaaction.org.uk/environments [Accessed September 2015].

Fisk, M. J. 2003. Social Alarms to Telecare: Older People's Service in Transition. Policy Press, Bristol, UK.

Fotaki, M. and Boyd, A. 2005. From plan to market: a comparison of health and old age care policies in the UK and Sweden. Public Money E Management, 25, 4, 237-43.

Gilleard, C. and Higgs, P. 2010. Frailty, disability and old age: a reappraisal. Health, $\mathbf{1 5}, 5,475^{-}-90$.

Gilleard, C. and Higgs, P. 2011 . Ageing abjection and embodiment in the fourth age. Journal of Aging Studies, 25, 2, 135-42.

Grosz, E. A. 1995. Space, Time, and Perversion: Essays on the Politics of Bodies. Routledge, London.

Grosz, E. 2001. Architecture from the Outside: Essays on Virtual and Real Space. MIT Press, Cambridge, Massachusetts.

Gubrium, J. F. 1997. Living and Dying at Murray Manor. University Press of Virginia, Charlotteville, Virginia.

Gubrium, J. F. and Holstein, J. A. 1999. The nursing home as a discursive anchor for the ageing body. Ageing $\mathcal{E}^{2}$ Society, 19, 5, 519-38.

Gullette, M. 1997. Declining to Decline: Cultural Combat and the Politics of the Midlife. University Press of Virginia, Charlottesville, Virginia.

Gutman, R. 2010. Professions and their discontents: the psychodynamics of architectural practice. In Cuff, D. and Wriedt, J. (eds), Architecture from the Outside In: Selected Essays by Robert Gutman. Princeton Architectural Press, New York, 43-6o.

Handler, S. 2014. An Alternative Age-friendly Handbook: For the Socially Engaged Practitioner. University of Manchester Library, Manchester, UK. Available online at http://www.micra.manchester.ac.uk/medialibrary/Age-friendlyHandbook_ LARGE\% 20PRINT\% 20VERSION.pdf [Accessed September 2015].

Heathcote, E. 2010. Architecture and health. In Jencks, C. and Heathcote, E. (eds), The Architecture of Hope. Frances Lincoln, London, 52-91.

Hockey, J. and James, A. 1993. Growing Up and Growing Old: Ageing and Dependency in the Life-course. Sage, London.

Holden, C. 2002. British government policy and the concentration of ownership in long-term care provision. Ageing $\mathcal{E}$ Society, 22, 1, 79-94. 
Homes and Communities Agency 2009. HAPPI Housing Our AgeingPopulation: Panel for Innovation. Homes and Communities Agency, London. Available online at https:// www.gov.uk/government/publications/housing-our-ageing-population-panel-forinnovation [Accessed January 2015].

Imrie, R. 2003. Architects' conceptions of the human body. Environment and Planning D, 21, 1, 47-65.

Imrie, R. 2004. Disability, embodiment and the meaning of the home. Housing Studies, 19, 5, 745-63.

Imrie, R. and Luck, R. 2014. Designing inclusive environments: rehabilitating the body and the relevance of universal design. Disability and Rehabilitation, 36, 16, $1315^{-9}$.

Jacobs, J. and Merriman, P. 2011. Practising architectures. Social E Cultural Geography, 12, 3, $211-22$.

Jamie, K. 2014. The pharmacy gaze: bodies in pharmacy practice. Sociology of Health and Illness, 36, 8, $114^{1-55}$.

Jones, P. 2011 . The Sociology of Architecture. Liverpool University Press, Liverpool, UK.

Jönson, H. 2012. We will be different: ageism and the temporal constitution of old age. The Gerontologist, 53, 2, 198-204.

Kelly, F. 2014. Bodywork in dementia care: recognising the commonalities of selfhood to facilitate respectful care in institutional settings. Ageing $\mathcal{E}$ Society, 34, 6, 1073-90.

Kerr, A. 2013. Body work in assisted conception: exploring public and private settings. Sociology of Health and Illness, 35, 3, 465-78.

Kouprie, M. and Sleeswijk-Visser, F. 2009. A framework for empathy in design: stepping into and out of the users' life. Journal of Engineering Design, 2o, 5, 437-48.

Latour, B. and Yaneva, A. 2008. Give me a gun and I will make all buildings move: an ANT's view of architecture. In Geiser, R. (ed.) Explorations in Architecture: Teaching, Design, Research. Birkhäuser, Basel, Switzerland, 80-9.

Laws, G. 1997. Spatiality and age relations. In Jamieson, A., Harper, S. and Victor, C. (eds), Critical Approaches to Ageing and Later Life. Open University Press, Buckingham, UK, 90-100.

Lawton, J. 1998. Contemporary hospice care: the sequestration of the unbounded body and 'dirty dying'. Sociology of Health and Illness, 2o, 2, $121-43$.

Leder, D. 1992. The Body in Medical Thought and Practice. Kluwer, Dordrecht, The Netherlands.

Lee-Treweek, G. 1997. Women, resistance and care: an ethnographic study of nursing auxiliary work. Work, Employment and Society, 11, 1, 47-63.

Lees, L. 2001. Towards a critical geography of architecture: the case of an ersatz Colosseum. Ecumene, 8, 1, 51-86.

Lupton, D. 2014. The commodification of patient opinion: the digital patient experience economy in the age of big data. Sociology of Health and Illness, 36, 6, 856-69.

Martin, D., Nettleton, S., Buse, C., Prior, L. and Twigg, J. 2015. Architecture and health care: a place for sociology. Sociology of Health and Illness, 37, 7, $1007-22$.

Milligan, C., Roberts, C. and Mort, M. 2011. Telecare and older people: who cares where? Social Science E् Medicine, 72, 3, 347-54.

Mol, A. 2002. The Body Multiple: Ontology in Medical Practice. Duke University Press, Durham, North Carolina.

Mol, A. 2008. The Logic of Care: Health and the Problem of Patient Choice. Routledge, London.

Mort, M., Roberts, C. and Callen, B. 2013. Ageing with telecare: care or coercion in austerity? Sociology of Health and Illness, 35, 6, 799-812. 


\section{$145^{6}$ Christina Buse et al.}

Murphy, K. M. 2004. Imagination as joint activity: the case of architectural interaction. Mind, Culture and Activity, 11 , 4, 267-78.

Oldman, C. and Quilgars, D. 1999. The last resort? Revisiting ideas about older people's living arrangements. Ageing E Society, 19, 3, 363-84.

Östlund, B. 2002. The deconstruction of a target group for IT-innovations: elderly users' technological needs and attitudes towards new IT. NätverketKulturforskning $i$ Uppsala, $1 \mathbf{1}, 77-93$.

Östlund, B. 2005. Design paradigms and misunderstood technology: the case of older users. In Jaeger, B. (ed.), Young Technologies in Old Hands: An International View on Senior Citizens Utilization of ICT. DJOF Publishing, Copenhagen, 25-39.

Pedwell, C. 2014. Affective Relations: The Transnational Politics of Empathy. Palgrave Macmillan, Basingstoke, UK.

Phillipson, C. and Powell, J. L. 2004. Risk, social welfare and old age. In Tulle, E. (ed.), Old Age and Agency. Nova, New York, 17-26.

Prentice, R. 2013. Bodies in Formation. Duke University Press, Durham, North Carolina.

Prior, L. 1988. The architecture of the hospital: a study of spatial organization and medical knowledge. British Journal of Sociology, 39, 1, 86-1 13.

Rees Jones, I. R. and Higgs, P. 2010. The natural, the normal and the normative: contested terrains in ageing and old age. Social Science $\mathcal{E}^{2}$ Medicine, 71, 8, 1513-9.

Rose, G., Degen, M. and Basdas, B. 2010. More on big things: building events and feelings. Transactions of the Institute of British Geographers, 35, 3, 334-49.

Sang, K. J., Dainty, A. R. and Ison, S. G. 2014. Gender in the UK architectural profession: (re)producing and challenging hegemonic masculinity. Work, Employment $\mathcal{E}^{\circ}$ Society, 28, 2, 247-64.

Schillmeier, M. and Domènech, M. 2009. Care and the art of dwelling: bodies, technologies, and home. Space and Culture, 12, 3, 288-91.

Selwyn, N. 2004. The information aged: a qualitative study of older adults' use of information and communications technology. Journal of Aging Studies, 18, 4, 369-84.

Sennett, R. 2009. The Craftsman. Penguin, London.

Sennett, R. 201 2. Together: The Rituals, Pleasures and Politics of Cooperation. Penguin, London.

Shapiro, J. 2008. Walking a mile in their patients' shoes: empathy and othering in medical students' education. Philosophy, Ethics and Humanities in Medicine, 3, 10. Available online at http://www.peh-med.com/content/3/1/10 [Accessed September 2015].

Shildrick, M. 2001. Embodying the Monster: Encounters with the Vulnerable Self. Sage, London.

Sloane, D. C. and Sloane, B. C. 2003. Medicine Moves to the Mall. Johns Hopkins University Press, Baltimore, Maryland.

Soldatic, K., Morgan, H., and Roulstone, A. (eds) 2014. Disability, Spaces and Places of Policy Exclusion. Routledge, London.

Suri, J. F. 2001. The next 50 years: future challenges and opportunities for empathy in our science. Ergonomics, 44, 14, 1278-89.

Torrington, J. 2006. What has architecture got to do with dementia care? Explorations of the relationship between quality of life and building design in two EQUAL projects. Quality in Ageing and Older Adults, 7, 1, 34-48.

Twigg, J. 2012. Adjusting the cut: fashion, the body and age on the UK high street. Ageing Eं Society, 32, 6, 1030-54.

Twigg, J. and Majima, S. 2014. Consumption and the constitution of age: expenditure patterns on clothing, hair and cosmetics among post-war 'baby boomers'. Journal of Aging Studies, 3o, 1, 23-32. 
Twigg, J., Wolkowitz, C., Cohen, R. L. and Nettleton, S. 201 1. Conceptualising body work in health and social care. Sociology of Health and Illness, 33, 2, 1 71-88.

Williams, S. J. 2000. Chronic illness as biographical disruption, or biographical disruptions as chronic illness? Reflections on a core concept. Sociology of Health and Illness, 22, 1, 40-67.

Woodward, K. 1991. Aging and its Discontents: Freud and Other Fictions. Indiana University Press, Bloomington, Indiana.

Ylänne, Y. 2012. Representing Ageing: Images and Identities. Palgrave Macmillan, Basingstoke, UK.

Accepted I I March 2о I6; first published online I9 May 2 I 6

Address for correspondence:

Christina Buse, Department of Sociology,

University of York, Heslington, York YO10 5 DD, UK

E-mail: christina.buse@york.ac.uk 